\title{
Efeito da tosquia estratégica no comportamento ingestivo de ovelhas Ile de France em pastagem de capim vaquero (Cynodon dactylon $\mathrm{cv}$ Vaquero) durante a estação de monta
}

\section{Effect of strategic shearing on feeding behavior in Ile de France sheep in Bermudagrass (Cynodon dactylon cv Vaquero) grazing during breeding season}

\author{
Luís Gabriel Alves Cirne ${ }^{1 *}$; Américo Garcia da Silva Sobrinho²; \\ Valéria Teixeira Santana ${ }^{3}$; Viviane Endo ${ }^{3}$; Fabiana Alves de Almeida ${ }^{3}$; \\ Mariana Rezende Franco ${ }^{3}$; Felipi Ulian Silva ${ }^{3}$; Emanuel Almeida de Oliveira ${ }^{2}$; \\ Gleidson Giordano Pinto de Carvalho ${ }^{4}$; Nivea Maria Brancacci Lopes Zeola ${ }^{5}$
}

\section{Resumo}

\begin{abstract}
O experimento foi conduzido com o objetivo de avaliar o efeito da tosquia estratégica no comportamento ingestivo de ovelhas Ile de France em pastagem de capim vaquero (Cynodon dactylon) durante a estação de monta. Foram utilizados 20 ovinos, fêmea, da raça Ile de France, com idade média de 4 anos, e peso corporal médio de $71,10 \mathrm{~kg}$, em pastejo, em delineamento experimental inteiramente casualizado, com dois tratamentos e dez repetições, em que os tratamentos foram constituídos de ovelhas tosquiadas e não tosquiadas. A duração da estação de monta foi de 90 dias, sendo que as avaliações ocorreram nos 86,87 e $88^{\circ}$ dia do período experimental. O tempo de pastejo (6,50 horas), ruminação (1,59 horas) e ócio $(3,97$ horas) não foram alterados $(\mathrm{P}>0,05)$ pela tosquia estratégica dos animais, assim como a frequência e o tempo por frequência de pastejo (18,33 pastejos e $21,49 \mathrm{~min} /$ pastejo), ruminação $(10,71$ ruminações e $8,83 \mathrm{~min} /$ ruminação) e ócio (18,83 ócios e 12,66 min/ócio). Da mesma forma, a quantidade de bocados por minuto (26,37 bocados) e o total de bocados diário (19.116 bocados) dos animais não foram afetados. Sendo assim, a tosquia estratégica em ovelhas Ile de France em pastagem de capim vaquero durante a estação de monta não altera o comportamento ingestivo dos animais.
\end{abstract}

Palavras-chave: Etologia, ovelhas, pastejo

\footnotetext{
Abstract

The experiment evaluated the effects of strategic shearing on feeding behavior in Ile de France ewes in Bermudagrass (Cynodon dactylon) grazing during breeding season. A total of 20 ewes, female, Ile de France breed, 4 years old, $71.10 \mathrm{~kg}$ of body weight, in grazing, in a completely randomized design with two treatments and ten repetitions, in which the treatments were composed by shorn and non-shorn

${ }^{1}$ Prof. e Pesquisador, Universidade Federal de Roraima, UFRR, Boa Vista, RR. E-mail: lgabrielcirne@hotmail.com

${ }^{2}$ Profs. e Pesquisadores, Universidade Estadual Paulista, UNESP, Jaboticabal, SP. E-mail: americo@fcav.unesp.br; moroto. oliveira@hotmail.com

${ }^{3}$ Discentes, UNESP, Jaboticabal, SP. E-mail: santana_vt@yahoo.com.br; endo_vica@hotmail.com; faalvesalmeida@yahoo.com. br; marirfranco@hotmail.com; slow_dr@yahoo.com.br

${ }^{4}$ Prof. e Pesquisador, Universidade Federal da Bahia, UFBA, Salvador, BA. E-mail: gleidsongiordano@yahoo.com.br

${ }^{5}$ Pesquisador, UNESP, Jaboticabal, SP. E-mail: nivea.brancacci@ig.com.br

* Autor para correspondência
} 
animals. The length of the breeding season was 90 days, where the evaluations occurred in the $86^{\text {th }}$, $87^{\text {th }}$ and $88^{\text {th }}$ day of the experimental period. The grazing time (6.50 hours), rumination ( 1.59 hours) and idle (3.97 hours) have not changed ( $\mathrm{P}>0.05)$ by strategic shearing of the animals, as well as the frequency and the time by frequency grazing (18.33 grazing and $21.49 \mathrm{~min} /$ grazing $)$, rumination (10.71 ruminations and $8.83 \mathrm{~min} /$ rumination) and idle (18.83 idles and $12.66 \mathrm{~min} / \mathrm{idle})$. In the same way, the number of bits per minute (26.37 bits) and the total daily bits $(19.116$ bits) of the animals were not affected. Thus, the strategic shearing in Ile de France ewes in Bermudagrass grazing during the breeding season does not alter animal feeding behavior.

Key words: Ethology, ewes, grazing

\section{Introdução}

A ovinocultura é uma atividade que está em constante expansão em regime de campo, e assim suas práticas de manejos intervêm no comportamento natural dos animais, uma vez que, o ecossistema de pastagens é caracterizado por uma série de inter-relações, regida por relações causaefeito (SARMENTO, 2003). Tal comportamento tem efeitos diretos sobre os padrões de consumo, disponibilidade de alimento, seleção e, por consequência, na produção (MEDEIROS et al., 2007).

Existem vários fatores que exercem influência sobre o comportamento ingestivo. Dentre eles, aqueles relacionados ao próprio animal, ao ambiente, ao manejo e à forragem disponível. Para Brancio et al. (2003), esta interação pode ser medida por meio de três características: tamanho de bocado, tempo de pastejo e taxa de bocado.

Segundo Silva e Carvalho (2005), é fundamental conhecer o animal como um todo, por isso, o conhecimento dos padrões de procura, escolha, localização e ingestão do alimento pelo animal são importantes, quando se pretende estabelecer práticas de manejo. $\mathrm{O}$ comportamento dos animais em pastoreio, dentre uma série de outras respostas, é seguramente uma parte importante do entendimento das relações planta-animal no ecossistema pastagem. Portanto, o estudo desse comportamento pode auxiliar de forma concisa na tomada de decisões relacionadas ao manejo das pastagens.

Hafez (1973) e Terrill (1973) comentaram que a tosquia pode aumentar a tolerância ao calor no verão, havendo uma possível relação entre a exposição a altas condições térmicas e uma melhora na capacidade de tolerância ao calor, possibilitando que o animal permaneça mais tempo em pastejo; porém, o esfriamento à sombra, pela ação do vento ou pela redução da temperatura ambiental, é mais rápido em animais tosquiados. Por outro lado, de acordo com Capeletto (2002), em animais lanígeros existe um gradiente térmico entre a pele e a superfície da lã, uma vez que a lã é péssima condutora de calor, e funciona como fornecedora de sombra para a ovelha.

Neste sentido, objetivou-se com o presente estudo avaliar o efeito da tosquia estratégica no comportamento ingestivo de ovelhas Ile de France em pastagem de capim vaquero (Cynodon dactylon cv Vaquero) durante a estação de monta.

\section{Material e Métodos}

O experimento foi desenvolvido no Setor de Ovinocultura do Departamento de Zootecnia da Faculdade de Ciências Agrárias e Veterinárias, FCAV - Unesp, Campus de Jaboticabal, SP, utilizando-se 20 ovinos, fêmea, da raça Ile de France, com idade média de 4 anos, e peso corporal médio de 71,10 kg.

A estação de monta teve duração de 90 dias, sendo seu início em 07/11/2011 e término em 05/02/2012, cuja proporção macho:fêmea foi de $2 \%$.

Os animais foram alocados em dois tratamentos, os quais foram constituídos de ovelhas tosquiadas e não tosquiadas, em que as ovelhas submetidas à tosquia estratégica foram esquiladas 3 semanas 
antes do início da estação de monta. Nos $86^{0}, 87^{0}$ e $88^{0}$ dia do período experimental foi avaliado o comportamento ingestivo dos animais com duração de $12 \mathrm{~h}$ cada (das $7 \mathrm{~h}$ às 19 horas).

Os tempos, as frequências e os tempos por frequências de pastejo, ruminação e ócio, assim como a quantidade de bocados por minuto e o total de bocados diários dos animais foram obtidos por meio de observações visuais, individual de todos os animais. As observações foram realizadas por duas pessoas treinadas, e com auxílio de binóculos a cada 10 minutos, em sistema de revezamento, posicionados estrategicamente de forma a não incomodar os animais, em que o tempo total foi o somatório do total de vezes em que os animais foram observados em determinado estado. Para facilitar a observação visual dos animais, estes foram identificados individualmente por meio de algarismos arábicos pintados sobre o velo em ambos os flancos e no lombo, com tinta spray de cor preta.

Os números de frequência de pastejo, ruminação e ócio foram contabilizados pelo número de sequências de atividades observadas na planilha de anotações. A duração média diária dessas frequências de atividades foi calculada dividindose a duração total de cada atividade (pastejo, ruminação e ócio em $\mathrm{min} / \mathrm{dia}$ ) pelo seu respectivo número de períodos discretos. A taxa de bocados (QBM) foi obtida por meio da contagem direta do total de bocados observados no período de 1 minuto, sendo a resultante da média de observações a cada meia hora, quando os animais estivessem pastejando (PARENTE et al., 2007; ZANINE et al., 2007). O total de bocados diários (TBD) foi calculado pelo produto entre a taxa de bocados e o tempo de pastejo, em minutos.

Os animais foram manejados em um módulo de pastagem de capim vaquero (Cynodon dactylon cv Vaquero) de dois hectares, divididos em cinco piquetes de 0,4 ha, contendo saleiro e bebedouro, manejado no método de lotação intermitente (rotativa), com período de descanso fixo de 20 dias.
Os animais foram mantidos em abrigos durante a noite, seguindo o manejo habitualmente empregado para os animais da instituição.

O clima de Jaboticabal é considerado, de acordo com classificação de Köppen, como subtropical do tipo CWA, mesotérmico com verão úmido e inverno seco, localizada a $21^{\circ} 15^{\prime} 22^{\prime \prime}$ de latitude Sul e 48 $18^{\prime} 58^{\prime \prime}$ de latitude Oeste, com altitude de $595 \mathrm{~m}$. Para caracterização da pastagem, a disponibilidade de forragem e a altura foi estimada antes da entrada e após a saída dos animais no piquete a ser pastejado, e as proporções (\%) de folha, colmo e material morto apenas na entrada. A massa de forragem e altura do pasto no pré e pós-pastejo foram estimadas mediante o método da dupla amostragem (HAYDOCK; SHAW, 1975), sendo feitos dez cortes, ao nível do solo, e medições de vinte alturas representativas ao acaso do piquete, sendo utilizada uma armação metálica de $0,25 \mathrm{~m}^{2}$ e uma régua graduada. A partir dos dez cortes simples, foram retiradas duas amostras compostas, em que uma foi secada em estufa com circulação de ar forçada a $55^{\circ} \mathrm{C}$, por 72 horas e, posteriormente, pesada para se estimar a disponibilidade de matéria seca total e a outra separada manualmente em lâmina foliar (a partir da lígula), pseudocolmo (colmo e bainhas) e material morto para estimar a proporção (\%) folha:colmo:material morto do pasto. A massa de forragem e a altura média do pasto, no pré e póspastejo, foram de $1.885 \mathrm{~kg} \mathrm{MS} / \mathrm{ha}$ e $20,75 \mathrm{~cm}$, e 947 $\mathrm{kg} \mathrm{MS} /$ ha e $12 \mathrm{~cm}$, respectivamente, e a proporção (\%) folha:colmo:material morto do pasto, no prépastejo, foi de 40:40:20, respectivamente.

A análise da fertilidade do solo (Tabela 1) foi determinada no laboratório de análises de solo, e a composição químico-bromatológica do pasto (Tabela 2) no Laboratório de Nutrição Animal, ambos pertencentes a FCAV - Unesp. Para análise do solo, foram retiradas 20 amostras ao acaso, na profundidade de $0-20 \mathrm{~cm}$, formando uma amostra composta, da qual foram retiradas $100 \mathrm{~g}$ para posterior análise, conforme metodologia descrita por Raij et al. (2001). 
Tabela 1. Análise química do solo do pasto de capim Vaquero.

\begin{tabular}{lc}
\hline Item & Resultados \\
\hline $\mathrm{pH}\left(\mathrm{CaCl}_{2}\right)$ & 5,4 \\
$\mathrm{Ca}\left(\mathrm{mmol}_{\mathrm{c}} / \mathrm{dm}^{3}\right)$ & 24,0 \\
$\mathrm{Mg}\left(\mathrm{mmol}_{\mathrm{c}} / \mathrm{dm}^{3}\right)$ & 12,0 \\
$\mathrm{~K}\left(\mathrm{mmol}_{\mathrm{c}} / \mathrm{dm}^{3}\right)$ & 0,9 \\
$\mathrm{P}$ resina $\left(\mathrm{mg} / \mathrm{dm}^{3}\right)$ & 14,0 \\
Matéria orgânica $\left(\mathrm{g} / \mathrm{dm}^{3}\right)$ & 16,0 \\
$\mathrm{H}+\mathrm{Al}\left(\mathrm{mmol}_{\mathrm{c}} / \mathrm{dm}^{3}\right)$ & 20,0 \\
Soma de bases $\left(\mathrm{mmol}_{\mathrm{c}} / \mathrm{dm}^{3}\right)$ & 36,9 \\
Capacidade de troca catiônica $\left(\mathrm{mmol}_{\mathrm{c}} / \mathrm{dm}^{3}\right)$ & 56,9 \\
Saturação de bases $(\%)$ & 65,0 \\
\hline
\end{tabular}

Fonte: Elaboração dos autores.

Tabela 2. Composição químico-bromatológica do pasto de capim Vaquero.

\begin{tabular}{lc}
\hline Item & Capim Vaquero \\
\hline Matéria seca & 22,1 \\
Matéria orgânica & 93,3 \\
Matéria mineral & 6,6 \\
Proteína bruta & 16,4 \\
Extrato etéreo & 2,2 \\
Lignina & 3,6 \\
Fibra em detergente neutro & 54,9 \\
Fibra em detergente ácido & 28,3 \\
\hline
\end{tabular}

Fonte: Elaboração dos autores.

Para a análise da composição químicobromatológica foram coletadas também 20 amostras aleatoriamente no pasto, por meio do pastejo simulado, formando, posteriormente, uma amostra composta, da qual foram retiradas 100 g para posterior análise de matéria seca (MS), matéria orgânica (MO), matéria mineral (MM) e extrato etéreo (EE), conforme metodologias descritas por Silva e Queiroz (2002). O teor de nitrogênio total da amostra foi obtido pelo método de combustão de Dumas, utilizando-se analisador LECO FP-528 LC, seguindo o procedimento descrito por Etheridge, Pesti e Foster (1998) e multiplicado por 6,25 para se obter o valor de proteína bruta (PB) total. Os teores de lignina, fibra em detergente neutro corrigida para cinzas e proteína (FDNcp) e fibra em detergente ácido (FDA), foram determinados de acordo com Van Soest (1994) e recomendados pelo fabricante do aparelho ANKOM Technology ${ }^{\circledR}$, utilizando-se sacos de ANKOM.

A variação da temperatura e umidade média diária (Figura 1) foi obtida a cada 10 minutos, utilizando-se um termômetro digital, de máxima e mínima, sendo este localizado à sombra, em abrigo montado exclusivamente para as mensurações.

As variáveis analisadas foram o tempo, a frequência e o tempo por frequência de pastejo, ruminação e ócio, a quantidade de bocados por minuto e o total de bocados por dia. O delineamento experimental utilizado foi o inteiramente casualizado, com dois tratamentos e dez repetições, totalizando 20 unidades experimentais. Os dados foram submetidos à análise de variância com comparação de médias pelo teste de Tukey a 5\% de probabilidade, conforme procedimentos do SISVAR (FERREIRA, 2000). 
Figura 1. Variação diária da temperatura e umidade média.

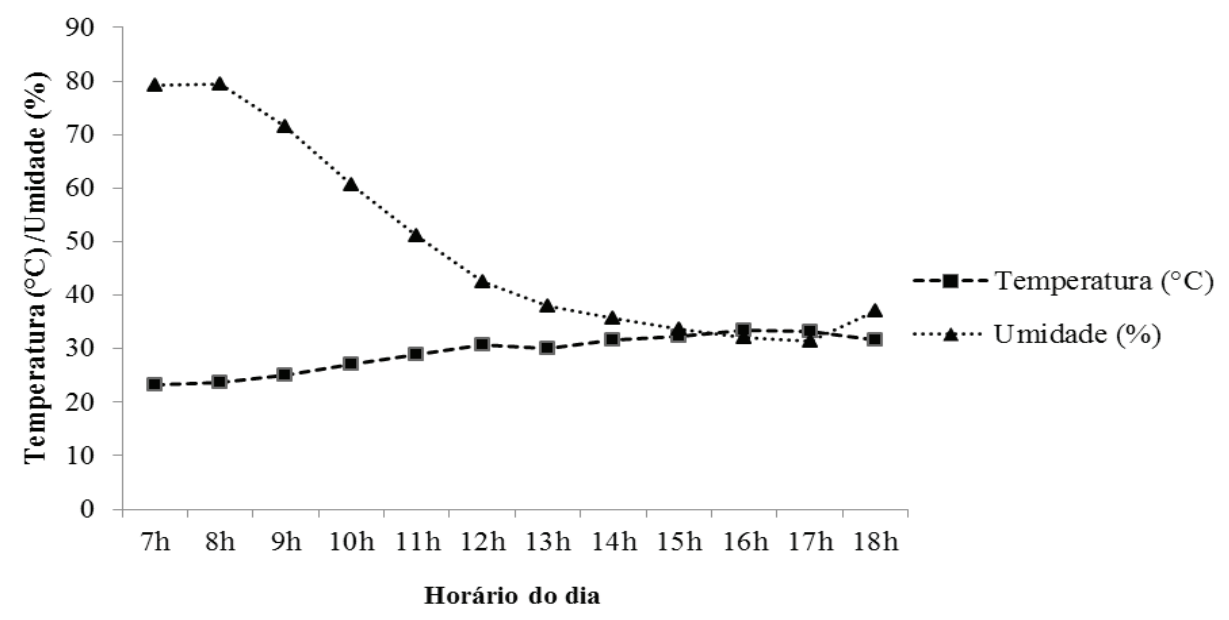

Fonte: Elaboração dos autores.

\section{Resultados e Discussão}

Os padrões de pastejo, ócio e ruminação (Figuras 2 e 3) ao longo do dia para as ovelhas tosquiadas e não tosquiadas, respectivamente, foram semelhantes, com picos de pastejo concentrados no início e final da manhã e no final do dia, e picos de ruminação concentrados logo após os picos de pastejo, no período da manhã às 9 h e no início da tarde às $13 \mathrm{~h}$. Esse comportamento apresentado pelos animais para atividade de ruminação corrobora a afirmação de Fraser e Broom (1990), em que a ruminação em ovinos ocorre em intervalos irregulares durante todo o dia, apresentando maior frequência de ruminação no início da manhã e tarde. Os animais permaneceram em ócio nos horários mais quentes do dia.

Figura 2. Variação no comportamento diário de pastejo, ruminação e ócio em ovelhas não tosquiadas em pasto de capim vaquero.

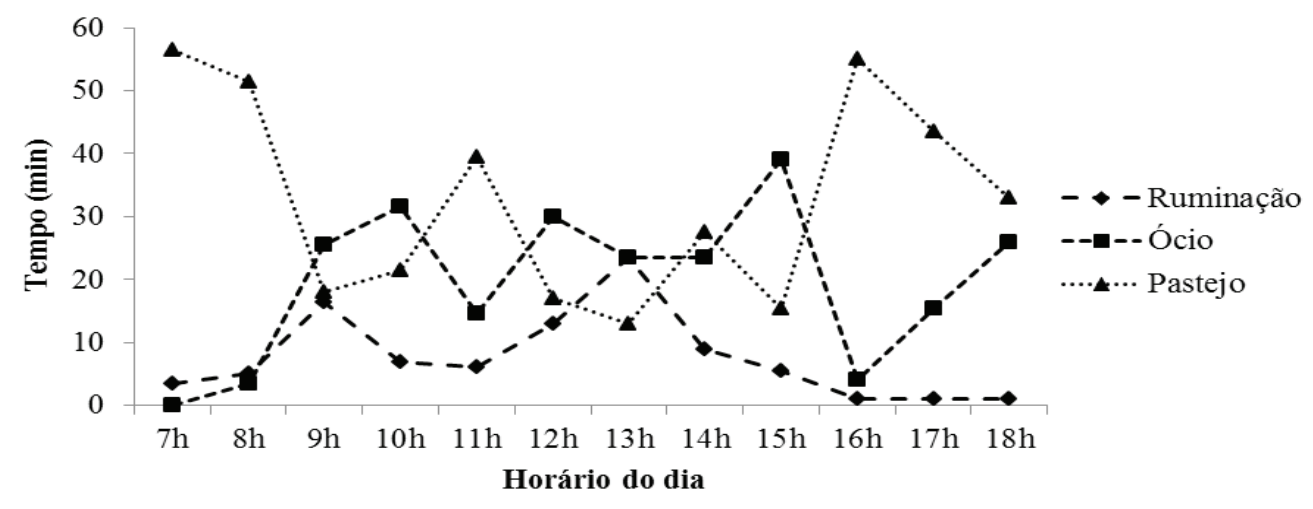

Fonte: Elaboração dos autores.

A atividade de pastejo apresentada pelos animais é semelhante às observadas por Cunha et al. (1997) e Parente et al. (2007), que, avaliando ovelhas Suffolk e Santa Inês em pastejo ao saírem dos abrigos, observaram que as mesmas iniciaram de imediato o pastejo, reduzindo progressivamente a partir das 
$11 \mathrm{~h}$ e $30 \mathrm{~min}$, retornando a partir das $13 \mathrm{~h}$ e 30 min e continuando até o final da tarde. BerggrenThommas e Hohenboken (1986) também verificaram comportamento similar, com maior porcentagem de animais em atividade de pastejo pela manhã e à tarde, com pouca atividade entre 11 e $14 \mathrm{~h}$.

Figura 3. Variação no comportamento diário de pastejo, ruminação e ócio em ovelhas tosquiadas em pasto de capim vaquero.

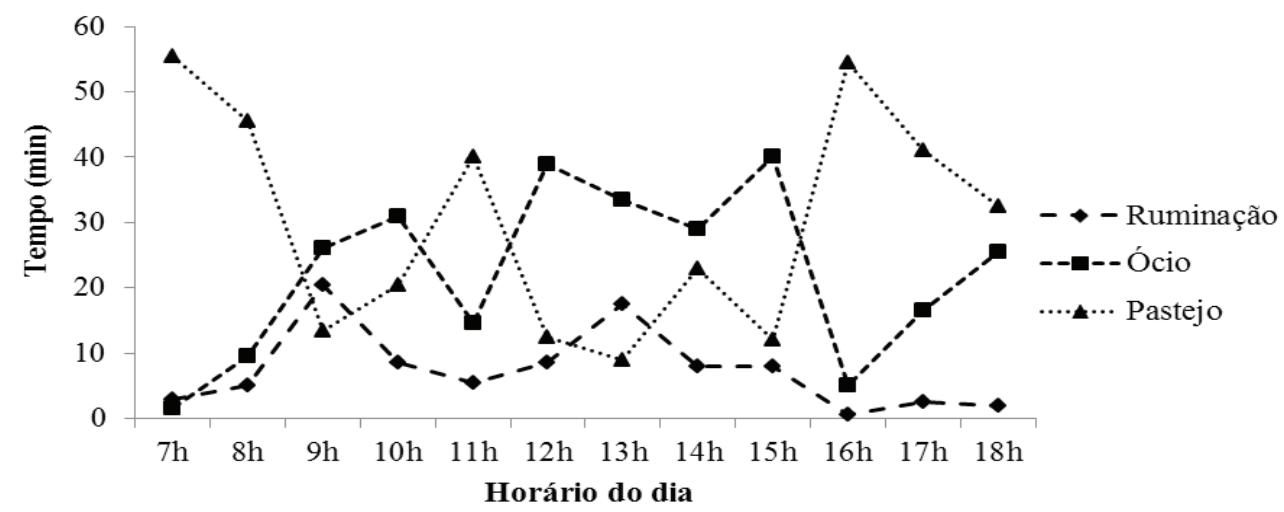

Fonte: Elaboração dos autores.

Os tempos diários despendidos nas atividades de pastejo, ruminação e ócio não foram influenciados $(\mathrm{P}>0,05)$ pela tosquia estratégica em ovelhas Ile de France em pastagem de capim vaquero durante a estação de monta; os valores médios registrados foram, respectivamente, de 6,50; 1,59 e 3,97 horas (Tabela 3).

O tempo despendido para a atividade de ruminação está de acordo com o relatado por Arnold e Dudzinki (1978), em que os ovinos gastam em média entre 1,5 a 10,5 horas por dia. Esses resultados estão próximos aos observados por Parente et al. (2007), que, ao avaliarem o comportamento ingestivo de ovellhas
Santa Inês em pastagem de tifton-85 (Cynodon ssp), observaram tempos médios de 7,08; 2,00 e 2,54 horas, respectivamente, para as atividades de pastejo, ruminação e ócio. As ovelhas que não foram tosquiadas não reduziram seu tempo de pastejo em pleno verão com temperatura máxima observada de $34^{\circ} \mathrm{C}$ (Figura 1), horário em que os animais estavam em plena atividade de pastejo (Figura 2). Possivelmente, esse comportamento observado seja em função de a lã funcionar como uma barreira física para a penetração da radiação até a pele, pois se trata de material isolante (SILVA, 2000).

Tabela 3. Tempo (hora) despendido em pastejo, ruminação e ócio em ovelhas Ile de France tosquiadas e não tosquiadas em pastagem de capim vaquero.

\begin{tabular}{lcccc}
\hline \multirow{2}{*}{ Item } & \multicolumn{2}{c}{ Grupo } & \multirow{2}{*}{$\mathrm{P}^{1}$} & \multirow{2}{*}{ CV (\%) ${ }^{2}$} \\
\cline { 2 - 3 } & Tosquiadas & Não tosquiadas & & \\
Pastejo & Tempo de atividade (hora) & 6,66 & 0,470 & 14,02 \\
Ruminação & 6,35 & 1,54 & 0,735 & 39,47 \\
Ócio & 1,64 & 3,87 & 0,630 & 23,10 \\
\hline
\end{tabular}

Médias não diferiram $(\mathrm{P}>0,05)$ pelo Teste Tukey.

${ }^{1} \mathrm{P}=$ probabilidade ${ }^{2} \mathrm{CV}=$ coeficiente de variação.

Fonte: Elaboração dos autores. 
Outro fator que poderia interferir no hábito de pastejo dos animais que não foram esquilados seria a umidade relativa do ar que se manteve alta até as 11 horas (Figura 1), período em que os animais apresentavam-se em intenso pastejo (Figura 2). Nos ovinos, a existência de um velo espesso dificulta a evaporação de umidade cutânea, ainda mais porque a lã é higroscópica e absorve o vapor d'água (VERÍSSIMO et al., 2009). Tal processo pode levar a considerável incremento na temperatura do velo, dificultar a termólise e aumentar o estresse do animal (KLEMM, 1962). Como consequência, a evaporação respiratória tem sido apontada como principal mecanismo de termólise nos ovinos (SILVA, 2000). No entanto, Silva e Starling (2003) verificaram a importância da evaporação cutânea, em ovinos lanados, cuja termólise em ambientes quentes, a evaporação respiratória seria um mecanismo fisiológico utilizado em respostas intensas por períodos mais curtos do dia. De fato, durante a observação visual dos animais, no período mais quente do dia (Figura 1), verificou-se que os mesmos apresentaram-se em intensa evaporação respiratória, coincidindo com o momento em que os mesmos estavam em ócio (Figura 2 e 3), o que sugere que esse comportamento seja um mecanismo de defesa dos animais lanígeros a altas temperaturas.

O número de frequência ( $\mathrm{n} \%$ dia) e o tempo gasto (min) por frequência de pastejo, ruminação e ócio não foram afetados $(\mathrm{P}>0,05)$, e os valores médios registrados foram, respectivamente, de $18,33 \mathrm{e}$ 21,$49 ; 10,71$ e 8,$83 ; 18,83$ e 12,66 (Tabela 4). Como os tempos médios por frequência de pastejo, ruminação e ócio são obtidos pela divisão do tempo total em 24 horas de cada atividade pelo número de frequências diárias, estas variáveis não sofreram alterações em função dos tratamentos.

A tosquia estratégica dos animais préencarneiramento, forma de "flushing" natural, tende a aumentar o consumo de matéria seca pelos animais, fazendo com que a ovelha ganhe peso. Diante disto, os animais melhoram as funções fisiológicas inerentes à reprodução, oferecendo condições adequadas à gestação (SIQUEIRA, 2001). Neste estudo, tal condição imposta às ovelhas pré-encarneiramento não alterou a discretização da série temporal de pastejo, ruminação e ócio das mesmas durante a estação de monta, sugerindo que esse manejo pode ser adotado sem comprometer o manejo diário dos animais.

Tabela 4. Frequências (n\%/dia) e do tempo gasto (min) por freqüência de pastejo, ruminação e ócio em ovelhas Ile de France tosquiadas e não tosquiadas em pastagem de capim vaquero.

\begin{tabular}{|c|c|c|c|c|}
\hline \multirow{2}{*}{ Item } & \multicolumn{2}{|c|}{ Grupo } & \multirow{2}{*}{$\mathrm{P}^{1}$} & \multirow{2}{*}{$\mathrm{CV}(\%)^{2}$} \\
\hline & Tosquiadas & Não tosquiadas & & \\
\hline \multicolumn{5}{|c|}{ Número de frequência (n⿳0/dia) } \\
\hline Pastejo & 17,55 & 19,11 & 0,185 & 13,02 \\
\hline Ruminação & 10,77 & 10,66 & 0,949 & 34,39 \\
\hline Ócio & 18,33 & 19,33 & 0,351 & 11,72 \\
\hline \multicolumn{5}{|c|}{ Tempo gasto por frequência (min) } \\
\hline Pastejo & 21,91 & 21,07 & 0,582 & 14,88 \\
\hline Ruminação & 9,13 & 8,54 & 0,472 & 19,13 \\
\hline Ócio & 13,36 & 11,96 & 0,232 & 18,86 \\
\hline
\end{tabular}

Médias não diferiram $(\mathrm{P}>0,05)$ pelo Teste Tukey. ${ }^{1} \mathrm{P}=$ probabilidade ${ }^{2} \mathrm{CV}=$ coeficiente de variação.

Fonte: Elaboração dos autores. 
Não houve diferença significativa $(\mathrm{P}>0,05)$ para a quantidade de bocados por minuto e o total de bocados diário de ovelhas Ile de France em pastagem de capim vaquero em função da tosquia estratégica (Tabela 5).

A quantidade média de bocados por minutos, de 26,37, foi próxima à observada por Parente et al. (2007), que, ao avaliarem o hábito de pastejo, de ovinos Santa Inês, em pastagem de capim tifton-85, observaram uma QBM de 24,38. Da mesma forma, a taxa média de bocados diários, de 19.116, corrobora com o registrado por Roman et al. (2007), que, ao estudarem o comportamento ingestivo, de ovelhas $1 / 2$ Ile de France 1/2 Texel, em pastejo, encontraram uma TBD de 21.935. Constrastando com os resultados dessa pesquisa, Pedroso et al. (2004), ao estudarem o comportamento ingestivo de ovelhas Corriedale com cordeiros ao pé, registraram uma QBM de 52,65. Provavelmente a maior QBM verificada por Pedroso et al. (2004), seja pelo fato de as ovelhas estarem com cordeiros ao pé, o que possivelmente reduziu a quantidade de forragem disponível para os animais, e os mesmos, para compensar essa redução de oferta de pasto, aumentaram a taxa de bocados (DE PAULA et al., 2009).

Tabela 5. Quantidade de bocados por minuto (QBM) e total de bocados diário (TBD) em ovelhas Ile de France em pastagem de capim vaquero.

\begin{tabular}{lcccc}
\hline \multirow{2}{*}{ Item } & \multicolumn{2}{c}{ Grupo } & \multirow{2}{*}{$\mathrm{P}^{1}$} & \multirow{2}{*}{ CV (\%) $)^{2}$} \\
\cline { 2 - 3 } & \multicolumn{2}{c}{ Tosquiadas } & Não tosquiadas & \\
$\mathrm{n}^{0} / \mathrm{min}$ & \multicolumn{2}{c}{ Quantidade de bocados } \\
$\mathrm{n}^{0} /$ dia & 26,10 & 26,64 & 0,664 & 9,87 \\
\hline
\end{tabular}

Médias não diferiram $(\mathrm{P}>0,05)$ pelo Teste Tukey.

${ }^{1} \mathrm{P}=$ probabilidade $;{ }^{2} \mathrm{CV}=$ coeficiente de variação.

Fonte: Elaboração dos autores.

\section{Conclusão}

A tosquia estratégica em ovelhas Ile de France em pastagem de capim vaquero durante a estação de monta não altera o comportamento ingestivo dos animais, podendo essa prática ser utilizada sem comprometer o manejo diário dos mesmos.

\section{Referências}

ARNOLD, G. W.; DUDZINKI, M. L. Ethology of freeranging domestic animals. Amsterdam: Elsevier, 1978. $198 \mathrm{p}$.

BERGGREN-THOMMAS, B.; HOHENBOKEN, W. D. The effects of sire-breed, forrage availability and weather on the grazing behaviour of crossbreed ewes. Applied Animal Behavior Science, Philadelphia, v. 15, n. 3, p. 217-228, 1986.
BRANCIO, P. A.; EUCLIDES, V. P. B.; NASCIMENTO JUNIOR, D. N.; FONSECA, D. M.; ALMEIDA, R. G.; MACEDO, M. C. M.; BARBOSA, R. A. Avaliação de três cultivares de Panicum maximum Jacq. sob Pastejo: comportamento ingestivo de bovinos. Revista Brasileira de Zootecnia, Viçosa, v. 32, n. 5, p. 1045-1053, 2003.

CAPELETTO, A. J. Bioclimatologia animal on line. São Paulo: Uni FMU, 2002. Disponível em: <http://www. bioclima.info/ovinos.php>. Acesso em: 3 mar. 2012.

CUNHA, E. A.; SANTOS, L. E.; RODA, D. S.; POZZI, C. R.; OTSUK, I. P.; BUENO, M. S.; RODRIGUES, C. F. C. Efeito do sistema de manejo sobre o comportamento em pastejo, desempenho ponderal e infestação parasitária em ovinos Suffolk. Pesquisa Veterinária Brasileira, Seropédica, v. 17, n. 3-4, p. 1005-1011, 1997.

DE PAULA, E. F. E.; STUPAK, E. C.; ZANATTA, C. P.; PONCHEKI, J. K.; LEAL, P. C.; MONTEIRO, A. L. G. Comportamento ingestivo de ovinos em pastagens: Uma revisão. Revista Tropica - Ciências Agrarias e Biologicas, Chapadinha, v. 4, n. 1, p. 42-51, 2009. 
ETHERIDGE, R. D.; PESTI, G. M.; FOSTER, E. H. A comparison of nitrogen values obtained utilizing the Kjeldahl nitrogen and Dumas combustion methodologies (Leco CNS 2000) on samples typical of an animal nutrition analytical laboratory. Animal Feed Science and Technology, Amsterdam, v. 73, n. 1, p. 21-28, 1998.

FERREIRA, D. F. Análises estatísticas por meio do Sisvar para Windows versão 4.0. In: REUNIÃO ANUAL DA REGIÃO BRASILEIRA DA SOCIEDADE INTERNACIONAL DE BIOMETRIA, 45., 2000, São Carlos. Anais... São Carlos: UFSCar, 2000. p. 255-258.

FRASER, A. F.; BROOM, D. M. Farm animal behaviour and welfare. London: Bailliere Tindall, 1990. $437 \mathrm{p}$.

HAFEZ, E. S. E. Adaptación de especies especificas. In: . Adaptación de los animales domésticos. Editorial Labor: Barcelona, 1973. p. 334-355.

HAYDOCK, K. P.; SHAW, N. H. The comparative yield method for estimating dry matter yield of pasture. Australian Journal of Experimental Agriculture and Animal Husbandry, East Melbourne, v. 15, n. 76, p. 663670, 1975.

KLEMM, G. H. The reactions of unshorn and shorn sheep to hot wet and hot dry atmospheres. Australian Journal Agricultural Research, Victoria, v. 13, n. 3, p. 472-478, 1962.

MEDEIROS, R. B.; PEDROSO, C. E. S.; JORNADA, J. B. J.; SILVA, M. A.; SAIBRO, J. C. Comportamento ingestivo de ovinos no período diurno em pastagem de azevém anual em diferentes estádios fonológicos. Revista Brasileira de Zootecnia, Viçosa, v. 36, n. 1, p. 198-204, 2007.

PARENTE, H. N.; ZANINE, A. M.; SANTOS, E. M.; FERREIRA, D. J.; OLIVEIRA, J. S. Comportamento ingestivo de ovinos em pastagem de Tifton 85 (Cynodon ss) na região Nordeste do Brasil. Ciência Animal Brasileira, v. 38, n. 2, p. 210-215, 2007.

PEDROSO, C. E. S.; MEDEIROS, R. B.; SILVA, M. A.; JORNADA, J. B. J.; SAIBRO, J. C.; TEIXEIRA, J. R. F. Comportamento de ovinos em gestação e lactação sob pastejo em diferentes estádios fenológicos de azevém Anual. Revista Brasileira de Zootecnia, Viçosa, v. 33, n. 5, p. 1340-1344, 2004.

RAIJ, B. V.; ANDRADE, J. C.; CANTARELLA, H.; QUAGGIO, J. A. Análise química para avaliação da fertilidade de solos tropicais. Campinas: Instituto Agronômico, 2001. 285 p.
ROMAN, J.; ROCHA, M. G.; PIRES, C. C.; ELEJALDE, D. A. G.; KLOSS, M. G.; OLIVEIRA NETO, R. A. Comportamento ingestivo e desempenho de ovinos em pastagem de azevém anual (Lolium multiflorum Lam.) com diferentes massas de forragem. Revista Brasileira de Zootecnia, Viçosa, v. 36, n. 4, p. 780-788, 2007.

SARMENTO, D. O. L. Comportamento ingestivo de bovinos em pastos de capim-Marandu submetidos a regimes de lotação contínua. 2003. Dissertação (Mestrado em Zootecnia) - Escola Superior de Agricultura Luiz de Queiroz. Universidade de São Paulo, Piracicaba.

SILVA, D. J.; QUEIROZ, A. C. Análise de alimentos: métodos químicos e biológicos. 3. ed. Viçosa: UFV, 2002. 235 p.

SILVA, R. G. Introdução à bioclimatologia animal. São Paulo: Nobel, 2000. 286 p.

SILVA, R. G.; STARLING, J. M. C. Evaporação cutânea e respiratória em ovinos sob altas temperaturas ambientes. Revista Brasileira de Zootecnia, Viçosa, v. 32, n. 6, p. 1956-1961, 2003.

SILVA, S. C.; CARVALHO, P. C. F. Foraging behaviour and herbage intake in the favourable tropics/sub-tropics. In: MCGILLOWAY, D. A. Grassland: a global resource. Wageningen: Wageningen Academic Publishers, 2005. p. 81-95.

SIQUEIRA, E. R. Manejo de matrizes em rebanhos produtores de carne. In: REUNIÃO ANUAL DA SOCIEDADE BRASILEIRA DE ZOOTECNIA, 38., 2001, Piracicaba. Anais... Piracicaba, 2001. v. 2, p. 447453.

TERRILL, C. E. Adaptación de los borregos y de las cabras. In: Adaptación de los animales domésticos. Barcelona: Editorial Labor, 1973. p. 334-355.

VAN SOEST, P. J. Nutritional ecology of the ruminant. New York: Cornell University Press, 1994. 476 p.

VERÍSSIMO, C. J.; KATIKI, L. M.; BUENO, M. S.; CUNHA, E. A.; MOURÃO, G. B.; TITTO, C. G.; PEREIRA, A. M. F.; TITTO, E. A. L. Tolerância ao calor em ovelhas Suffolk e Ile de france antes e após a tosquia. Boletim de Indústria Animal, Nova Odessa, v. 66, n. 1, p. 61-66, 2009.

ZANINE, A. M.; SANTOS, E. M.; PARENTE, H. N.; FERREIRA, D. J.; CECON, P. R. Hábito de pastejo de vacas lactantes Holandês x Zebu em pastagens de Brachiaria brizantha e Brachiaria decumbens. Arquivo Brasileiro de Medicina Veterinária e Zootecnia, Belo Horizonte, v. 59, n. 1, p. 175-181, 2007. 
